\title{
ITER monoblock performance under lifetime loading conditions in Magnum-PSI
}

\author{
T.W. Morgan ${ }^{1,}{ }^{*}$, M. Balden ${ }^{2}$, T. Schwarz-Selinger ${ }^{2}$, Y. Li ${ }^{1.3}$, Th. Loewenhoff ${ }^{4}$, M. \\ Wirtz $^{4}$, S. Brezinsek ${ }^{4}$ and G. De Temmerman ${ }^{5}$ \\ ${ }^{1}$ DIFFER - Dutch Institute for Fundamental Energy Research, De Zaale 20, 5612 AJ Eindhoven, the \\ Netherlands \\ ${ }^{2}$ Max-Planck-Institut für Plasmaphysik, Boltzmannstr. 2, 85748 Garching, Germany \\ ${ }^{3}$ Eindhoven University of Technology, Department of Mechanical Engineering, Groene Loper 3 \\ 5612 AE, Eindhoven, Netherlands \\ ${ }^{4}$ Forschungszentrum Jülich, Institut für Energie- und Klimaforschung, 52425 Jülich, Germany \\ ${ }^{5}$ ITER Organization, Route de Vinon sur Verdon, CS90 046, 13067 St Paul Lez Durance Cedex, France \\ E-mail: *t.w.morgan@differ.nl
}

Received xxxxxx

Accepted for publication $\mathrm{xxxxxx}$

Published xxxxxx

\begin{abstract}
The ITER divertor will be exposed to extremely high plasma fluences over its lifetime, and it is known that plasma exposure can lead to a variety of particle-induced surface-morphology and microstructure changes in tungsten. However, no data exists at fluences comparable to those expected over extended ITER operations $\left(10^{30-31} \mathrm{~m}^{-2}\right)$ and so it is uncertain how these changes will evolve and affect the divertor performance over such long timescales. Six monoblocks were exposed to high flux plasma comparable to partially-detached plasma conditions in the ITER divertor in Magnum-PSI. Different exposures used different plasma species $(\mathrm{H}, \mathrm{He}, \mathrm{D}$ or $\mathrm{D}+\mathrm{He})$ and aimed to replicate conditions similar to those during different phases of the ITER staged approach. The highest fluence achieved was $10^{30} \mathrm{D} \mathrm{m}^{-2}$, comparable to around one year of ITER Fusion Power Operation. Post-mortem analysis by Nuclear Reaction Analysis revealed very low deuterium retention throughout the blocks, while surface analysis showed no cracking or damage, but did observe helium fuzz growth at low ion energies of 8-18 eV, below typically assumed ion energy requirements for such growth to occur. Metallographic sectioning revealed recrystallization up to $2.2 \mathrm{~mm}$ below the surface of monoblocks exposed at peak surface temperatures of up to $1580^{\circ} \mathrm{C}$ for different durations up to $\sim 20$ hours. Finite Element Method analysis coupled to metallographic and Vickers Hardness identification of the boundary of the recrystallized region identified a faster recrystallization process compared to literature expectations, reinforcing that recrystallization dynamics is an important criterion for tungsten grade selection for the ITER divertor. Overall, no major damage or failure was identified, indicating that the design is capable of fulfilling its steady-state performance requirements under high flux, high fluence plasma loading conditions in the ITER divertor.
\end{abstract}

Keywords: Divertor, ITER, tungsten, Magnum-PSI, recrystallization 


\section{Introduction}

The development of fusion power relies on a robust and reliable heat exhaust system with walls which can withstand extreme heat and particle fluxes. The next generation fusion reactor, ITER, will be much larger than existing devices and heat loads up to $20 \mathrm{MW} \mathrm{m}^{-2}$ must be withstood by the walls of the heat exhaust system (divertor) [1,2]. In ITER the plasma facing components of the divertor consist of tungsten (W) monoblocks bonded to a water cooled CuCrZr cooling tube $[3,4]$.

Plasma exposure of $\mathrm{W}$ can generate strong morphology changes such as blistering [5-10], sputter erosion [11-13] and nanotendril (fuzz) formation [13-20]. However, little data is available on the effect of high plasma fluences on the morphology, thermal and mechanical properties of $\mathrm{W}$, particularly for actively cooled samples where thermodiffusion may dominate the permeation flow of the plasma species. However, it is anticipated that the ITER divertor will receive a fluence of $10^{30-31} \mathrm{~m}^{-2}$ during its service lifetime, far in excess of the highest values achieved in existing tokamaks or linear plasma devices up to this point [21]. Following the installation of a superconducting magnetic field coil at the high flux linear plasma device Magnum-PSI $[22,23]$, this regime is now accessible for the first time.

ITER will commence operations following a staged approach [24]. In the two pre-fusion power operational (PFPO) stages experiments will be carried out with hydrogen $(\mathrm{H})$ and helium (He) plasma only, with higher heating powers available in the latter stage (increasing from 20-30 MW to 7383 MW), typically at half-field half-current for H-mode discharges. In the fusion power operation (FPO) stages deuterium (D) and then deuterium-tritium (D-T) plasma operations will be carried out in H-mode at full-field fullcurrent to generate significant fusion power, producing also He which will be removed via the divertor. In consequence it is expected that the divertor will receive much higher heat loads in this latter stage and that the divertor will need to operate at high densities and with seeding impurities to keep the peak heat loads to tolerable levels.

Six plasma exposures were carried out in Magnum-PSI $[22,23,25]$, with the goal to closely simulate the effect of plasma exposure at the divertor strikepoints in different phases of the ITER staged approach. The heat and particle loads were chosen based on cases from the ITER SOLPS simulations database $[21,26]$. The highest fluence case was up to $10^{30} \mathrm{~m}^{-2}$, which is approximately 1 year of FPO operation ( 2500 400s $\mathrm{QDT}_{\mathrm{DT}}=10$ discharges) [21]. The samples were then characterized to analyse surface morphology changes, D retention and microstructural evolution with the goal to determine the effect that long fluence plasma exposure has on monoblock performance.

\section{Experimental}

\subsection{Monoblock mock-up chain}

A mock-up chain provided by Fusion for Energy (F4E) and produced by Plansee SE, consisting of seven W monoblocks (MBs) mounted on a CuCrZr pipe, was used to carry out the experimental loading. The blocks had front and back faces of $21 \times 12 \mathrm{~mm}$ with a total thickness of $28 \mathrm{~mm}$. On the front side (F) the depth to the cooling tube from the block centre was 8 $\mathrm{mm}$ while on the back side (B) this was $6 \mathrm{~mm}$. The blocks were brazed to a $12 \mathrm{~mm}$ outer diameter CuCrZr pipe with a 1 $\mathrm{mm} \mathrm{Cu}$ interlayer. The mock-up otherwise conformed to the reference geometry given in [2] and was produced as part of the same series as those used in [27]. The surface of the blocks had a technical finish and the blocks were exposed as received without additional treatment apart from cleaning with water and alcohol before exposure.

\begin{tabular}{|c|c|c|c|c|c|c|c|c|c|c|c|}
\hline Block & $F / B$ & $\begin{array}{l}\text { Nominal } \\
\text { ITER } \\
\text { stage }\end{array}$ & Species & $\begin{array}{l}T_{p k} \\
\left({ }^{\circ} C\right)\end{array}$ & $\begin{array}{l}\left\langle\Gamma_{p k}\right\rangle \\
\left(10^{24} m^{-}\right. \\
\left.{ }^{2} \mathrm{~s}^{-1}\right)\end{array}$ & $\begin{array}{l}\Phi_{p k} \\
\left(10^{29}\right. \\
\left.m^{-2}\right)\end{array}$ & $\begin{array}{l}q_{p k} \\
\left(M W m^{-}\right. \\
\left.{ }_{2}\right)\end{array}$ & $\begin{array}{l}q_{\perp} \\
\left(M W m^{-}\right. \\
\left.{ }_{2}^{2}\right)\end{array}$ & $\begin{array}{l}t_{\exp } \\
\text { (h) }\end{array}$ & Int. & Order \\
\hline MB1 & & & None & & & & & & & & \\
\hline MB3 & $\mathrm{F}$ & PFPO1 & $\mathrm{H}$ & $\begin{array}{l}750 \\
\pm 15\end{array}$ & $\begin{array}{l}1.23 \\
\pm 0.25\end{array}$ & $\begin{array}{l}1.00 \\
\pm 0.07\end{array}$ & $\begin{array}{l}13.2 \\
\pm 0.3\end{array}$ & 6.0 & 22.6 & 2 & $1^{\text {st }}$ \\
\hline MB4 & B & PFPO2 & $\mathrm{He}$ & $\begin{array}{l}1050 \\
\pm 20\end{array}$ & $\begin{array}{l}2.93 \\
\pm 0.52\end{array}$ & $\begin{array}{l}0.25 \\
\pm 0.07\end{array}$ & $\begin{array}{l}19.5 \\
\pm 0.3\end{array}$ & 8.5 & 2.9 & 1 & $5^{\text {th }}$ \\
\hline MB2 & B & FPO1 & $\mathrm{D}$ & $\begin{array}{l} \pm 20 \\
\pm 45\end{array}$ & $\begin{array}{l}10.3 \\
\pm 1.6\end{array}$ & $\begin{array}{l}4.10 \\
\pm 0.07\end{array}$ & $\begin{array}{l}27.1 \\
\pm 0.3\end{array}$ & 12.7 & 11.2 & 2 & $6^{\text {th }}$ \\
\hline MB5 & $\mathrm{F}$ & FPO1 & $\mathrm{D}$ & $\begin{array}{l} \pm 4580 \\
\pm 45\end{array}$ & $\begin{array}{l} \pm 1.0 \\
\pm 2.3\end{array}$ & $\begin{array}{l}10.10 \\
\pm 0.07\end{array}$ & $\begin{array}{l}24.6 \\
\pm 0.3\end{array}$ & 12.8 & 19.7 & 7 & $2^{\text {nd }}$ \\
\hline MB7 & $\mathrm{F}$ & FPO2-3 & $\begin{array}{l}\mathrm{D}: \mathrm{He} \\
(95: 5)\end{array}$ & $\begin{array}{l} \pm 45 \\
\pm 45\end{array}$ & $\begin{array}{l} \pm 2.3 \\
\pm 1.1\end{array}$ & $\begin{array}{l}2.79 \\
\pm 0.07\end{array}$ & $\begin{array}{l}24.0 \\
\pm 0.3\end{array}$ & 12.7 & 6.5 & 0 & $3^{\text {rd }}$ \\
\hline MB6 & B & FPO2-3 & $\begin{array}{l}\mathrm{D}: \mathrm{He} \\
(95: 5)\end{array}$ & $\begin{array}{l}1555 \\
\pm 45\end{array}$ & $\begin{array}{l}12.5 \\
\pm 1.1\end{array}$ & $\begin{array}{l}5.02 \\
\pm 0.07\end{array}$ & $\begin{array}{l}27.9 \\
\pm 0.3\end{array}$ & 12.6 & 17.8 & 1 & $4^{\text {th }}$ \\
\hline
\end{tabular}

Table 1: Experimental conditions for each monoblock position. $\left\langle\Gamma_{p k}\right\rangle$ and $\Phi_{p k}$ denote the average plasma flux and cumulative fluence at the beam centre, respectively. $q_{p k}$ is the average peak power at the beam centre determined using FEM (section 2.3) and $q_{\perp}$ is the equivalent $q_{\perp}$ in ITER which would produce the same surface temperature, taking into account cassette tilting and shaping. $t_{\text {exp }}$ is the cumulative exposure time, Int. denotes the number of interruptions in the exposures due to e.g. realignment of diagnostics or between different days and Order the order of exposures. 


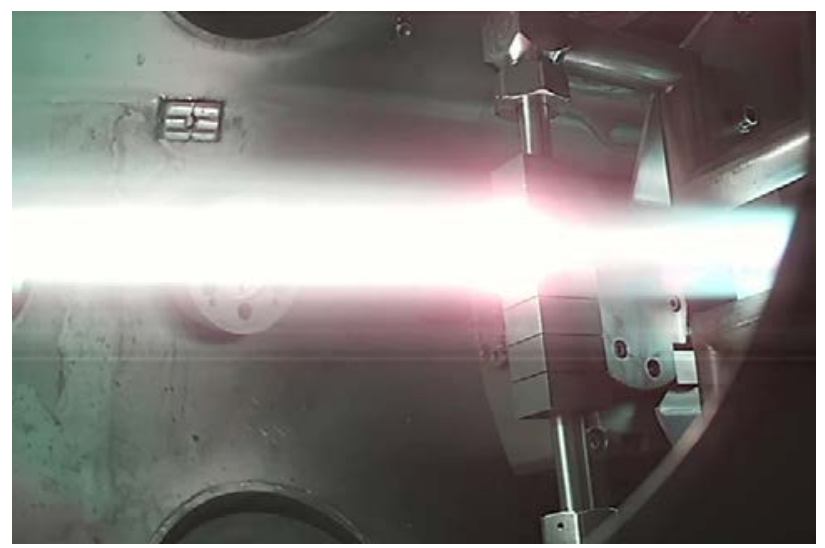

Figure 1: Still from video of D plasma exposure of MB5

\subsection{Plasma exposure and diagnostics}

Plasma species as well as source and magnet settings were varied to generate a series of different conditions conforming to the different staged approach phases. The different exposure conditions are given in Table 1. For the case with mixed $\mathrm{D}$ and $\mathrm{He}$ the ratio given is the gas input ratio.

The Magnum-PSI plasma beam is Gaussian in shape with a typical full-width at half maximum (FWHM) of 11-14 mm for hydrogen, deuterium and helium plasmas. Therefore the exposure positions were chosen so that only every second block was exposed in a given $\mathrm{F}$ or B series while front/back exposure positions were also staggered so that each block only received a single exposure (Figure 2). This made each loading as independent as possible while maximizing the number of exposures which could be carried out. As can be seen in Figure 1 the plasma beam has a visible extent of $\sim 30 \mathrm{~mm}$ which broadens close to the target due to recycling, but which predominantly intersects the block of interest and the adjacent blocks only. The maximal possible extent is limited to $<10 \mathrm{~cm}$ by the diameter of the skimmer $\sim 37 \mathrm{~cm}$ in front of the target [28].

Following the exposures on the front face, impurities, particularly Sn, were observed as depositions on regions of the sample ([29] and section 3.2.2). This was present due to crosscontamination from experiments involving $\mathrm{Sn}$ prior to these exposures. Therefore an extensive cleaning of the machine was carried out and a second set of exposures on the back face were subsequently carried out, in this case with a strongly reduced observed Sn presence.

Plasma conditions were monitored using Thomson scattering (TS) to determine $T_{e}$ and $n_{e}$ as a function of radius and time at a location $\sim 25 \mathrm{~mm}$ upstream from the exposed surface. This therefore enabled the determination of the particle flux from the Bohm criterion as

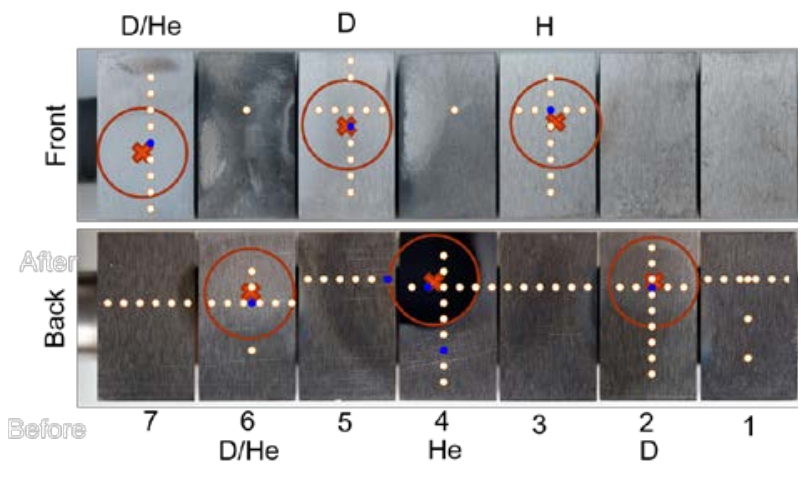

Figure 2: Photographs of the plasma-exposed front and back faces of the monoblock chain. The red x's mark the plasma spot centre while the red circles indicate the FWHM of the plasma beam. The white and blue spots show the positions scanned over during the NRA measurements.

$$
\Gamma=\sin \theta \frac{1+M_{u}{ }^{2}}{2} n_{e} \sqrt{\frac{k_{B}\left(T_{e}+\chi_{i} T_{i}\right)}{\left\langle m_{i}\right\rangle}}
$$

where $\theta$ is the angle of the magnetic field lines with respect to the target surface, $M_{u}$ the Mach number at the TS location, $\chi_{i}=5 / 3$ the polytropic coefficient and $\left\langle m_{i}\right\rangle$ the average ion mass. It is assumed that $M_{u}=0, T_{e}=T_{i}$ and that there are no significant energy loss channels between the TS position and the target surface. The cumulative fluence was determined as $\Phi=\int \Gamma(\mathrm{t}) \mathrm{d} t$. The time-averaged flux $\left(\left\langle\Gamma_{p k}\right\rangle\right)$ and overall fluence $\left(\Phi_{p k}\right)$ at beam centre are given in Table 1 .

Source settings were varied moderately during long exposures in order to maintain a surface temperature within $\pm 25^{\circ} \mathrm{C}$ of the nominal temperature, but a characteristic range of conditions can be given. For MB3 the characteristic electron temperature, $\left[T_{e}\right]$, and electron density, $\left[n_{e}\right]$, at the plasma centre were $0.77-0.79 \mathrm{eV}$ and $1.3-2.1 \times 10^{20} \mathrm{~m}^{-3}$ respectively, while for MB4 the values were $\left[T_{e}\right]=2.8-3.2 \mathrm{eV}$ and $\left[n_{e}\right]=3.6-4.8 \times 10^{20} \mathrm{~m}^{-3}$. For MBs 2, 5, 6 and 7 similar settings were used with characteristic values $\left[T_{e}\right]=1.87-1.99$ $\mathrm{eV}$ and $\left[n_{e}\right]=14.0-17.8 \times 10^{20} \mathrm{~m}^{-3}$. This range of conditions is the main contributor to the uncertainty in the average peak flux $\left(\left\langle\Gamma_{p k}\right\rangle\right)$, while typical uncertainties are $5 \%$ and $6 \%$ for $T_{e}$ and $n_{e}$ respectively, which is the main contributor to the uncertainty in the peak fluence $\left(\Phi_{p k}\right)$.

The surface temperature of the blocks was monitored using two diagnostics. First, an infrared (IR) camera (FLIR SC7500MB, 3.97-4.01 $\mu \mathrm{m}, 10 \mathrm{~Hz}$ ) viewing the full front surface and surrounding monoblocks. Second, a single-chord multi-wavelength pyrometer (FAR-Associates FMPI SpectroPyrometer) with an elliptical viewing region with major and minor diameters of $6 \mathrm{~mm}$ and $4 \mathrm{~mm}$ respectively, positioned at the location of the plasma beam centre on the monoblock. This finite viewing region results in an underestimate of the maximum surface temperature at the 
beam centre $\left(T_{p k}\right)$ by $\sim 25^{\circ} \mathrm{C}$ and this effect is already taken into account in Table 1 . The pyrometer was calibrated using a black body (Heitronics SW11B) which operated up to 1000 ${ }^{\circ} \mathrm{C}$ and the values and errors given in Table 1 for $T_{p k}$ reflect this calibration and the uncertainty in extrapolating the calibration above $1000{ }^{\circ} \mathrm{C}$. Peak surface temperatures are representative of the upper end of the range of heat loads expected during the different stages of ITER operation explored on each block [21].

Impurities in the plasma were monitored using survey (299$950 \mathrm{~nm}$ ) optical emission spectroscopy (OES, Avantes AvaSpec-2048-USM2-RM) using a viewing-chord focused on the target surface. Total power to the target was determined using cooling water calorimetry.

\subsection{Post-mortem analysis}

Initial post-mortem characterization was carried out on the plasma-exposed surfaces using the Bombardino set-up at the tandem accelerator of Max-Planck-Institut für Plasmaphysik (IPP), which can accommodate such large samples without prior sectioning.

Nuclear Reaction Analysis (NRA) using $690 \mathrm{keV}{ }^{3} \mathrm{He}$ ions (probing depth $\sim 500 \mathrm{~nm}$ ) was carried out over 35 locations on the front face and 62 locations on the back face to determine the retained $\mathrm{D}$ near the surface. The beam spot FWHM was $1.8 \mathrm{~mm}$. The scanned positions are marked in Figure 2 using the white spots. The closed blue symbols indicate where measurements were performed in addition with $1.2 \mathrm{MeV}, 1.8$ $\mathrm{MeV}, 2.4 \mathrm{MeV}, 3.2 \mathrm{MeV}$ and $4.5 \mathrm{MeV}^{3} \mathrm{He}$ ions to determine the $\mathrm{D}$ depth profile down to $7.2 \mu \mathrm{m}$.

Surface analysis was performed at IPP using Confocal Laser Scanning Microscopy (CLSM) and Scanning Electron Microscopy (SEM). Energy-Dispersive X-ray spectroscopy (EDX) was used to quantify observed impurity species while Focused Ion Beam (FIB) was used to prepare cross sections in the sample. More details of this analysis are presented in [29] and only the most important observations are addressed below.

Following these analyses the mock-up was cut, cross sections of MBs 2-7 were prepared and metallography was performed using the same technique as in [30]. An example is shown in Figure 5(c). Furthermore Vickers Hardness (HV5) was used to map hardness changes horizontally at a depth 0.5 $\mathrm{mm}$ below the surface and vertically downwards under the plasma beam centre with a spacing of $0.5 \mathrm{~mm}$ (Figure 5(c)). Additional HV30 measurements were also carried out on MB5 and MB2 close to the cooling tube and on the uncut side of MB1 to characterize the unmodified grain hardness and evaluate any size effects.

Additional NRA via line scan between the copper cooling tube and the centre of the plasma exposed surface was also executed on the sectioned material using $2.4 \mathrm{MeV}{ }^{3} \mathrm{He}$ ions

\begin{tabular}{l|ccccccll}
\multicolumn{2}{l}{ Block: } & 1 & 2 & 3 & 4 & 5 & 6 & 7 \\
\hline F & $\Phi_{\text {ret }}$ & & & 4.6 & 3.3 & 2.8 & 8.7 & 2.0 \\
& $f$ & & & & & 2.8 & & 5 \\
$B$ & $\Phi_{\text {ret }}$ & 3.6 & 3.4 & 5.5 & 3.2 & 7.7 & 0.05 & 2.8 \\
& $f$ & & 8.2 & & & & 0.1 &
\end{tabular}

Table 2: Maximum $D$ retained areal density $\left(\Phi_{\text {ret }}, 10^{20} \mathrm{D} \mathrm{m}^{-2}\right)$ on each block as measured by NRA (top row) and retained fraction $\left(f=\Phi_{\text {ret }} / \Phi_{p k}, 10^{-10}\right)$

(probing depth $3.3 \mu \mathrm{m}$ ). Four (back) or five (front) positions were examined as a function of distance from the plasma exposed surface for each block (Figure 5(c)). Beam spot size was $1.0 \mathrm{~mm}$ FWHM in this case.

The temperature throughout the monoblock was determined using Finite Element Method (FEM) analysis with MSC.Marc/Metat ${ }^{\circledR}$. Temperature-dependent thermal conductivity and heat capacity were adopted from the ITER material handbook (v3.3) [31]. A convection boundary condition was applied on the inner surface of the CuCrZr pipe with a film coefficient of $100 \mathrm{~kW} \mathrm{~K}^{-1} \mathrm{~m}^{-2}$ and a coolant temperature of $20^{\circ} \mathrm{C}$. A Gaussian face flux was applied on the top surface of the block, with the same FWHM as that of the TS measurement. The centre position of the Gaussian heat flux was initialized using the IR camera observations then iterated to match the symmetry of the observed microstructure changes (section 3.3.2). The magnitude of the Gaussian heat flux was adjusted such that the resulting top surface temperature matched the corresponding pyrometer measurements.

\section{Results and discussion}

\subsection{Surface and depth profile NRA}

Table 2 shows the results of the surface NRA scans, carried out over the regions shown in Figure 2. They clearly indicate that D retention ( $\left.\Phi_{\text {ret }}\right)$ everywhere is rather moderate. Compared to the exposure fluences the retained fractions $(f=$ $\left.\Phi_{\text {ret }} / \Phi_{\mathrm{pk}}\right)$ on the blocks exposed to D or D+He are extremely small, in the range $0.1-8 \times 10^{-10}$. This is in line with expectations, as retention has been shown to be very small for high exposure temperatures [6,32], though higher flux plasma exposures typically show a higher temperature limit before no $\mathrm{D}$ is found [33]. Additionally, here only the top $\sim 0.5 \mu \mathrm{m}$ is probed while for long timescales and high temperatures deep inward diffusion will typically spread the retained D to large depths [8]. However, for all examined samples the depth profiles also show no detectable D signal, implying a D concentration below 5 appm. However, given the high surface temperatures for the $\mathrm{D}$ and $\mathrm{D}+\mathrm{He}$ exposures, the fraction able to diffuse to such depths and be trapped there is plausibly low enough to be undetectable more than a few $\mu \mathrm{m}$ below the surface. Additionally the chance for $\mathrm{D}$ to escape via transport to the edge of the monoblock is non-negligible as the distance to the cooling tube is similar to the distance to the side-walls. 
In all cases there are no clear differences between He seeded exposures and pure $\mathrm{D}$ exposures, despite the known propensity for He to form nanobubbles which can modify D transport in W [34-38].

Typically the position of highest retention on a given block was not in the centre, and the retention levels were rather uniform on all areas of the block. Given also that similar or even greater retention levels are found on blocks which were not directly exposed to $\mathrm{D}$ plasma, this implies that an additional source of D comes indirectly from crosscontamination from the wings of the plasma beam. Although, as shown in Figure 1 the beam is predominantly covering only the exposed and adjacent blocks, at a radius $r=25 \mathrm{~mm}$ from the beam centre (a spacing of two blocks) $\Gamma / \Gamma_{p k}=1.5 \times$ $10^{-5}$. This therefore equates to $\Gamma \approx 2 \times 10^{20} \mathrm{~m}^{-2} \mathrm{~s}^{-1}$ for the exposure on MB5, giving $\Phi \approx 1.5 \times 10^{25} \mathrm{D} \mathrm{m}^{-2}$ on MB3, at which point the surface temperature of such a block is close to room temperature due to negligible plasma heating. At $300 \mathrm{~K}$ retention of order $\Phi_{\text {ret }} \sim 10^{20} \mathrm{D} \mathrm{m}^{-2}$ with such an exposure fluence, as observed, is fully compatible with the available literature [6,8]. Additionally deep diffusion should not be expected under these circumstances as the implantation depth is very shallow and the block temperature low. Here impurity deposition may also be playing a role in limiting inwards diffusion (section 3.2.2).

Cross-contamination can also account for the results for MB6. On the back-side it was exposed to high fluence of $\mathrm{D}+\mathrm{He}$ at temperatures up to $1555^{\circ} \mathrm{C}$ and shows extremely small retention $\left(5 \times 10^{18} \mathrm{D} \mathrm{m}^{-2}\right)$. The centre of MB6 was $\sim 10$ $\mathrm{cm}$ away from the centre of MB2 where the other high fluence $\mathrm{D}$ exposure on the back side was subsequently carried out which is too far away to lead to cross contamination $\left(\Gamma / \Gamma_{p k}=\right.$ $\left.1 \times 10^{-14}\right)$. All other blocks measured were no more than 2 blocks distant from the centre of a high fluence $\mathrm{D}$ or $\mathrm{D}+\mathrm{He}$ exposure. This therefore implies that retention rates under high temperature, high flux loading conditions in ITER should be expected to be more similar to MB6 than the others where cross contamination between exposures appears to dominate.

\subsection{Surface modifications}

A detailed discussion of the surface modifications is given in [29] and only the most important features are discussed here.

\subsubsection{Surface topology}

From CLSM, SEM and FIB it is found that the initial surface topology is dominated by the grinding grooves from the monoblock factory preparation, leading to a layer around $5 \mu \mathrm{m}$ thick of strongly distorted and tiny grains $(\ll 1 \mu \mathrm{m})$, followed by slight distortion up to several tens of $\mu \mathrm{m}$, on top of the undistorted grain structure. No cracks are observed anywhere on the surface, which was expected as no large transient loading was applied and therefore expected strains

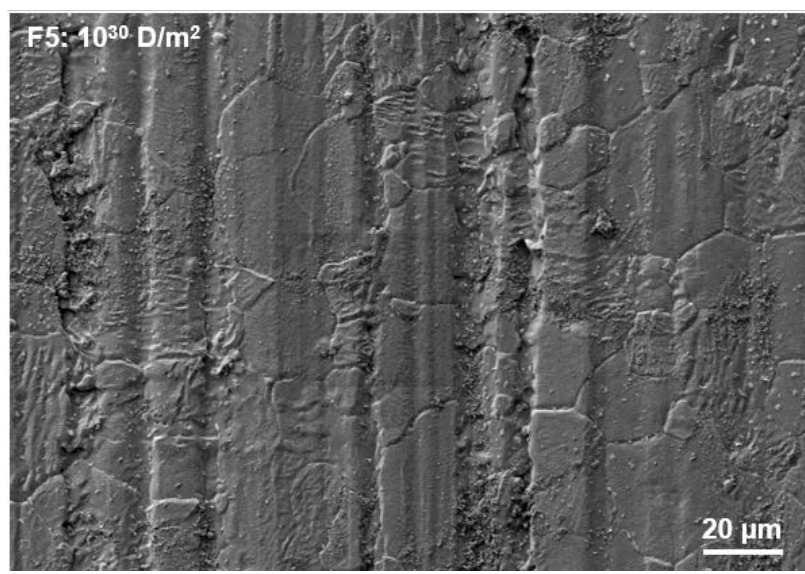

Figure 3: SEM image of the centre of MB5 (front) following plasma exposure. The original technical finish is still observable as well as strongly enlarged grains compared to the original submicron grain structure, clearly indicating recrystallization.

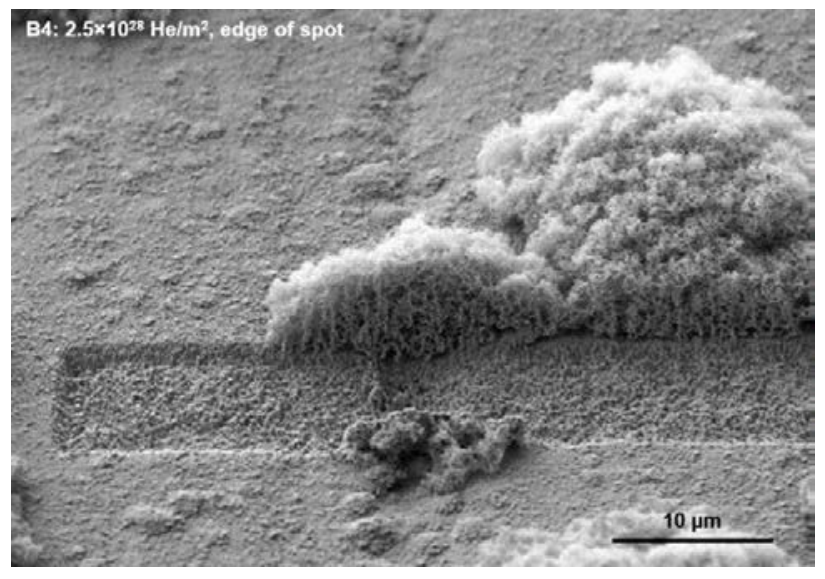

Figure 4: SEM image of FIB cut through fuzz islands at the edge of the fuzz-growth region on MB4.

are small and plastic deformation should be negligible. A recrystallization region of around $1-2 \mathrm{~cm}^{2}$ centred on the beam spot locations of blocks 2,5,6, and 7 can be determined based on observed grain enlargement (Figure 3 ). This is discussed further in section 3.3.2.

\subsubsection{Impurity deposition}

Thin layers of impurity deposition up to around $100 \mathrm{~nm}$ in thickness were observed via FIB-SEM and EDX, with different impurities predominant at different areas on the surfaces. The dominant impurities are $\mathrm{Mo}, \mathrm{Sn}, \mathrm{Cu}, \mathrm{Fe}$ and $\mathrm{Cr}$. Mo and Sn are found in all regions to a greater or lesser extent, and both were observed to have a strong variation between different grains on the recrystallized regions. Additionally Mo decorated the grain boundaries in these regions to a depth of up $20 \mu \mathrm{m}$. Cu, Fe and $\mathrm{Cr}$ are more localized to certain regions of the mock-up. As discussed earlier the Sn observed can be traced to prior Sn experiments in Magnum-PSI. Most 
plausibly $\mathrm{Cu}$ and $\mathrm{Mo}$ come from the plasma source while $\mathrm{Fe}$ and $\mathrm{Cr}$ are clustered together, implying a source from steel, the most likely being the target holder. Overall, the impurity levels are rather low given the high fluences involved. This can be estimated as a density concentration of $10^{-7}-10^{-9}$ if a sticking probability of unity (typical for metals) is assumed once they arrive at the surface. The impurities do not seem to give any modifications to the underlying material (excepting the Mo grain boundary decoration), particularly as ion energies were too low (section 3.2.3) for sputtering to be significant.

\subsubsection{Helium nano-fuzz formation}

A clear blackened region can be observed on MB4 (Figure 2). SEM analysis shows that this region is covered with Hefuzz. In the centre the fuzz thickness is $\sim 3 \mu \mathrm{m}$ while at the edge it increases to $8 \mu \mathrm{m}$. The fuzz-covered region extends around $7 \mathrm{~mm}$ from the beam centre and corresponds to the region with surface temperature $>750{ }^{\circ} \mathrm{C}$. This agrees well with the literature expectations for the required temperature window for such growth [16].

The ion impact energy under floating conditions can be estimated as

$$
E_{\text {ion }} \simeq E_{k}-e V_{f} \approx 5.5 k_{B} T_{e}
$$

where $E_{k} \approx 2.5 k_{B} T_{i}$ is the ion kinetic energy to the surface and $e V_{f} \approx-3 k_{B} T_{e}$ the ion acceleration through the sheath and we assume $T_{e}=T_{i}$ [39]. For the electron temperature of $\left[T_{e}\right]=2.8-3.2 \mathrm{eV}$ at the plasma centre this gives $E_{\text {ion }} \approx 15-$ $18 \mathrm{eV}$. At the edge of the fuzz growth region $T_{e}$ is only around $1.5 \mathrm{eV}$ giving $E_{\text {ion }} \approx 8 \mathrm{eV}$. Particularly in this edge region the ion energy is well below that expected to give rise to fuzz which is typically taken to be $>20 \mathrm{eV}$ [16], but is quite close to the observed threshold for He bubble formation $(9 \mathrm{eV})$ [40]. The plasma potential across the radius of the beam may, however, have been non-uniform, which could lead to somewhat higher ion energies than expected in equation (2) [41,42]. Previously observed ion energy thresholds [16] and incubation fluences $[19,43]$ were determined in much lower flux and fluence experiments which may therefore not have been able of revealing fuzz growth under similar exposure conditions. Given the hypothesis that observed incubation fluence is driven by the requirement to reach a critical level of He in the near surface layer before fuzz can grow [44,45], this may have a variation with ion energy that can only be observed at these high fluences.

Based on the scaling for $\mathrm{W}$ fuzz layer thickness of Petty [19] with corrections for annealing [46] and taking the effective diffusion coefficient for $1320 \mathrm{~K}$ from [15] (close to the central surface temperature of $1050{ }^{\circ} \mathrm{C}$ ) we can estimate that the expected fuzz thickness $d$ should be $\sim 43 \mu \mathrm{m}$ at the centre. This is effectively equivalent to scaling the simple onedimensional fuzz growth law $d=\left(2 D t^{\prime}\right)^{1 / 2}$ by a factor of $t^{\prime}=t f$ where $f \sim\left\langle\Gamma_{\mathrm{pk}}\right\rangle / \Gamma_{[15]} \sim 59$ accounts for the higher flux in this experiment than in [15]. Given the low ion energy, sputtering by beam impurities, which would reduce the growth rate, is below threshold, and so a different process is likely driving and limiting the fuzz growth.

One possible driver of fuzz growth can be the observed Mo deposition from the plasma. A high Mo fraction is observed in the fuzz (ratio W:Mo varies across the exposure spot and is mostly between 0.3 and 1.0) [29]. It was found in [47] that W sputtered into the plasma upstream and deposited greatly enhanced the fuzz growth rate, giving rise to $\mathrm{mm}$ long nanotendrils. A similar action may be taking place here, though the $\mathrm{W}$ present throughout the fuzz shows it is clearly also redistributing from the base of the fuzz as it grows as is demonstrated in [48]. Mo forms fuzz in the temperature range between 525 and $1000{ }^{\circ} \mathrm{C}[49,50]$ which may help to account for the thinner fuzz thickness in the centre, where, unlike for W, Mo-based fuzz would anneal compared to the edge where growth may be more dominant. However, it is unclear whether the high Mo levels observed are the driver of fuzz growth or are coincidental.

At the edge of the fuzz growth region there is not a clear boundary, instead the fuzz starts to form isolated islands, typically $\sim 10 \mu \mathrm{m}$ in diameter and $\sim 5 \mu \mathrm{m}$ high, surrounded by a modified but non-fuzzy W surface (Figure 4). Although much smaller in scale than nano-tendril bundles observed in $[51,52]$ these "fuzz balls" show a similar stochastic growth behaviour, implying that the conditions for fuzz formation are fulfilled only at certain surfaces in this region. In [52] the authors speculate that the grain orientation dependence for $\mathrm{W}$ modification by He [53] leads to preferential growth surfaces. Here it was found that all fuzz balls have a similar and high Mo concentration while the surrounding region has a similar and low Mo concentration, perhaps indicating a similar mechanism. However, it is unclear whether this localization is what leads to fuzz-ball growth or whether the fuzz is more efficient at retaining Mo on its surfaces, leading to the higher Mo concentration.

For MB6 and MB7, exposed to D+He plasma, no fuzz is observed, despite the clear OES observation of He content in the beam, that the temperature of exposures is sufficient for fuzz to occur and in contrast to expectations based on literature [17]. Although $\mathrm{T}_{\mathrm{pk}}$ was close to the temperature for fuzz annealing (1900-2000 K [54,55]) temperatures in the surrounding regions should be dominated by growth over annealing [46]. The He:D ion density ratio can be roughly estimated from the line intensity ratios between $\mathrm{He}^{0}$ $(k=447.9 \mathrm{~nm})$ and $\mathrm{D}^{0}(k=388.8,383.5$ and $379.9 \mathrm{~nm})$ emission lines from OES as

$$
\frac{n_{H e^{+}}}{n_{H^{+}}} \approx \frac{\int I_{H e^{+}}^{k} \mathrm{~d} \lambda}{\int I_{H^{+}}^{k} \mathrm{~d} \lambda} \frac{\mathcal{P}_{H^{+}}^{k}}{\mathcal{P}_{H e^{+}}^{k}}
$$


where $\int I_{j}^{k} \mathrm{~d} \lambda$ is the wavelength integrated photon count and $\mathcal{P}_{j}^{k}$ is the photon emissivity coefficient for recombination of species $j$ respectively via emission at wavelength $k$ [56]. We assume here that recombination emission is dominant for $\mathrm{H}^{0}$ and $\mathrm{He}^{0}$ emission, and that the emission volumes of the two species are similar. Using the lines listed above gives a ratio $n_{\mathrm{He}^{+}} / n_{\mathrm{H}^{+}} \approx 0.8-1.2 \%$. The reasonable agreement between the three $\mathrm{D}$ lines gives some confidence as to the result. This amount should still be sufficient for fuzz to form with a thickness of several $\mu \mathrm{m}$ [17]. In this case the plasma temperatures were somewhat lower (typically $\sim 2 \mathrm{eV}$ ) which may possibly also play a role in preventing fuzz formation,, though this is still higher than the electron temperature at the edge of the fuzz forming region on MB4. Alternatively, if Mo is playing a role in fuzz formation, these temperatures would be above the annealing temperature for fuzz formation by Mo and therefore this would explain the lack of fuzz observed.

\subsection{Metallography and recrystallization}

\subsubsection{Initial microstructure and Vickers hardness}

The metallography of the cross sections of MBs 3 and 4 enabled an examination of the initial microstructure as exposure temperatures were well below those expected for recrystallization to take place. Clear differences between the 

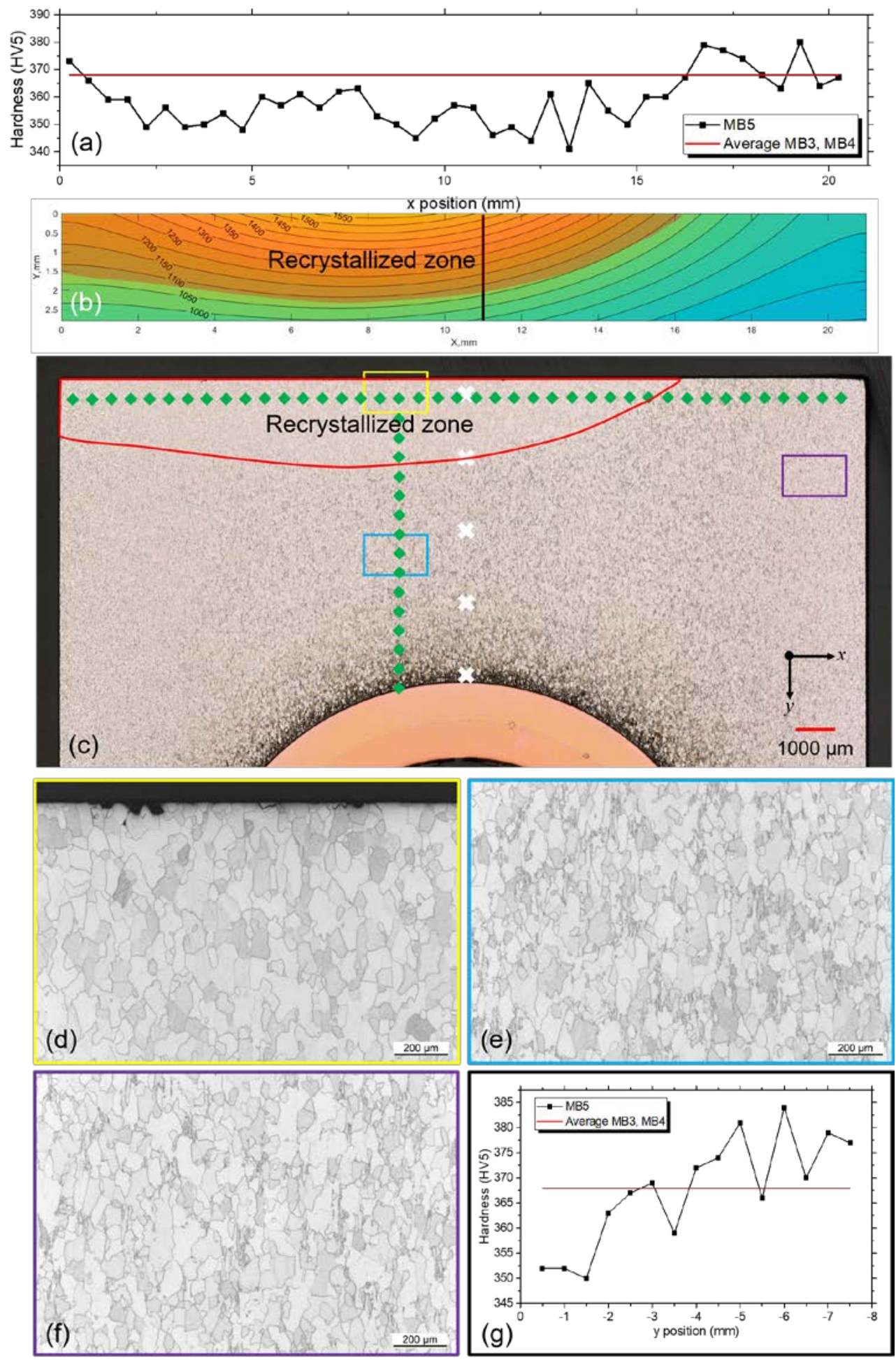

Figure 5: (a) Horizontal Vickers Hardness (HV5) measurement of MB5 compared to the average un-recrystallized value; (b) subsurface temperature contour plot from MSC.Marc/Metat ${ }^{\circledR}$. FEM calculation overplotted with the outline of the recrystallized region; (c) optical microscope image of MB5 metallographic cross section; SEM images of (d) the recrystallized microstructure, (e) the unmodified microstructure in the centre and $(f)$ at the edge.; $(g)$ Vertical Vickers Hardness (HV5) measurement of MB5 compared to the average unrecrystallized value. The positions of the SEM images shown in (d, e, f) are marked in (c) as yellow (top), blue (bottom) and purple (right) boxes, respectively. The white crosses indicate the positions of the depth-profile NRA and the green diamonds the positions where HV5 measurements were carried out.

centre and edges of the blocks were observed on these two and 
all other blocks. In the centre a bimodal grain structure was observed with clusters of small grains $(\sim 10 \mu \mathrm{m})$ and much larger grains $(50-200 \mu \mathrm{m})$, with a clear elongation towards the exposed surface (Figure 5(e)). At the edges many fewer small grains are observed with slightly more equiaxed grain shapes (Figure 5(f)). Horizontal Vickers hardness maps of MB3 and MB4 (i.e. following the same $x$-direction path as shown by the green diamonds in (Figure 5 (e)) show an initial hardness of $370 \pm 11$ and $366 \pm 8$ HV5 respectively. Selective HV30 measurements of regions where recrystallization did not occur: close to the cooling tube of MB5 and MB2 and on the outside of MB1, give values of $382 \pm 3,399 \pm 4$ and $372 \pm 10$ HV30 respectively. This is much lower than the ITER requirements (410 HV30 (ASTM E92)) and also shows significant variation from block to block.

\subsubsection{Recrystallization of monoblocks}

MBs 2, 5, 6 and 7 all were exposed with peak surface temperatures and durations above the literature values for recrystallization to typically occur [57-59]. The extent of recrystallization can be readily seen in regions where this occurs on the monoblocks due to the disappearance of small grains and growth of larger and more equiaxed grains (Figure 5(d)). This corresponds well with the surface observations (Figure 2). The boundary of this region was mapped from the images of the metallography cross sections (both from microscope and SEM (Figure 5(c)) and from HV5 measurements (Figure 5(a),(g)), which show a clear softening from $\sim 368 \pm 10$ to $\sim 353 \pm 6$ HV5.

Using the FEM analysis the recrystallized region could be mapped to the temperature inside the monoblock. Because recrystallization fraction typically displays a sigmoidal evolution with time, with fast progression to the fully recrystallized state once the incubation and recovery phases are completed, it is estimated that the border of the recrystallized region is the position where the recrystallization fraction $X=0.5$ is satisfied (Figure 5(b)). This is in good agreement with the Vickers Hardness measurements (Figure 5(a) and (g)), but we use the mapping due to better spatial resolution. The temperature at this position $(T)$ for a given time to half-recrystallization $\left(t_{X=0.5}=t_{\text {exp }}\right)$ can be compared to literature values for moderately (67\% rolling reduction [57]) and highly (90\% rolling reduction [58]) deformed W. In these cases $X=0.5$ for a given $t$ and $T$ was determined through a temporal series of isothermal annealing using the measured Vickers hardness determinations $H V=X H V_{\text {rec }}+$ $(1-X) H V_{0}$ where $H V_{\text {rec }}$ and $H V_{0}$ are the recrystallized and original Vickers hardness values before and after the recrystallization is complete. The results show that $t_{X=0.5}$ is lower at a given temperature $T$. The activation kinetics follows an Arrhenius relationship and can therefore be determined as

$$
t_{X=0.5}=A \exp \left(Q_{X=0.5} / k_{B} T\right) .
$$

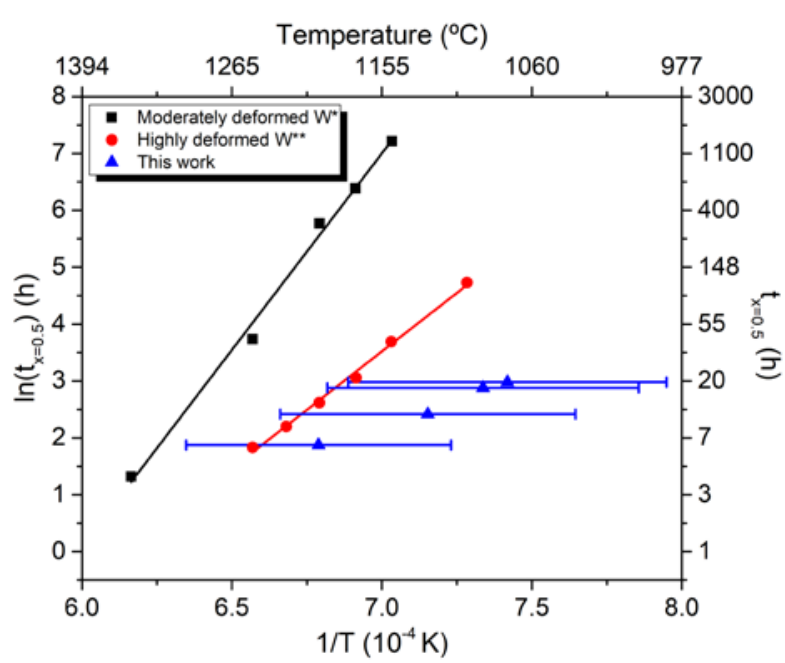

Figure 6: Time to half recrystallization as a function of temperature for moderately (*[40]) and highly (**[41]) deformed furnace annealed $W$ and for the monoblocks in this work.

In this case fitting the data in Figure 6 gives $Q_{X=0.5}=150$ $\mathrm{kJ} \mathrm{mol}^{-1}$ compared to $342 \mathrm{~kJ} \mathrm{~mol}^{-1}$ for highly deformed $\mathrm{W}$ and $575 \mathrm{~kJ} \mathrm{~mol}^{-1}$ for moderately deformed W. Therefore there seems to be a faster recrystallization kinetics compared to even the highly-deformed $W$, which this grade most resembles, though given the error bar there are large uncertainties. This error derives partially from the uncertainty in $T_{p k}$ and partially from uncertainties in defining the recrystallization boundary. Such an observed deviation can potentially be due to differences between different $\mathrm{W}$ grades, which can often show significant recrystallization and mechanical differences [59,60].

Another difference is the exposure to D or D+He plasma, rather than furnace annealing. Plasma exposure by He has previously been shown to have a retarding effect on recrystallization kinetics [61]. Potentially $\mathrm{H}$-isotopes could have an accelerating effect, as has been found for some hydride forming metals $[62,63]$. However, given the unusual and variable microstructure present in these blocks, as well as the experimental uncertainties, this requires dedicated experimental investigation.

\section{Implications for ITER divertor operation}

Overall the monoblocks performed well, with no failure and no clear damage, in line with expectations. The lack of retained $\mathrm{D}$, particularly at depth, is also positive, given that loss of tritium via permeation into the cooling system is a potential issue $[64,65]$.

The formation of fuzz observed here implies the possibility that it may also occur in the ITER divertor, even in fully 
detached regions where ion energies are only a few $\mathrm{eV}$ and it was previously assumed it would not grow. If impurity deposition from upstream is acting to aid the growth, it may be anticipated that $\mathrm{W}$ migration in the divertor could act similarly. Whether fuzz is detrimental to ITER divertor operation is still an open question however [21]. Based on the single observation here, a conclusion on the formation mechanism or lack thereof for fuzz and fuzz-balls cannot be reached, and dedicated experiments are recommended to explore this further.

Macrocracking has been observed due to near-surface recrystallization to a depth of 1-2 mm [60]. The cracking correlates with susceptibility to recrystallization, and the cracks may be of concern as a risk for leading edge melting [66]. The fast recrystallization kinetics found here would also imply recrystallization to a deeper depth more quickly than expected from previous furnace annealing studies [57,58]. Given the unusual and non-ITER grade microstructure of these materials, however, it would be beneficial to carry out dedicated experiments with well characterized material to fully investigate this, and also implies that recrystallization kinetics should be an important criterion for $\mathrm{W}$ grade choice for the ITER divertor procurement.

\section{Summary and conclusions}

A small-size mock-up of the ITER divertor plasma-facing units, consisting of seven tungsten monoblocks brazed to a CuCrZr cooling tube, was exposed to a variety of high fluence, high flux plasma loads in Magnum-PSI. Six of the blocks were exposed to a H, He, D or D:He (95:5) plasma with low electron temperature (1-3 eV) and high electron density $\left(2 \times 10^{20}\right.$ $1.8 \times 10^{21} \mathrm{~m}^{-3}$ ), with maximum surface temperatures in the range $750-1580{ }^{\circ} \mathrm{C}$. The exposures aimed to closely replicate partially detached conditions expected at the divertor strikepoints during different operational phases of the ITER staged approach [24]. The largest fluence achieved, $10^{30} \mathrm{D} \mathrm{m}^{-}$ 2 in 19.7 hours, is equivalent to around one year of Fusion Power Operation.

Post-mortem analysis focused on how such long-term exposures affected the microstructure and mechanical properties of each monoblock. NRA of the top surfaces revealed that the $\mathrm{D}$ retained fraction in the top $0.5 \mu \mathrm{m}$ was very low, always below $6 \times 10^{-10}$, while retained $\mathrm{D}$ was below detection levels ( $<5$ appm) throughout the bulk.

As expected no plasma induced cracking was observed, though analysis is obscured due to the rough surface finish and impurity deposition. For the He exposed block a nano-fuzz region was formed despite the rather low ion energy $(<18 \mathrm{eV}$ due to floating conditions), which is typically assumed to be below that required for fuzz formation. Cross-sectioning and metallography of each block permitted depth profiles of retained $\mathrm{D}$ and identification of the recrystallized region for the samples exposed at $\sim 1550{ }^{\circ} \mathrm{C}$ to be made. Using FEM analysis this was mapped to the temperature distribution throughout the monoblock, indicating an accelerated recrystallization kinetics compared to furnace recrystallized W. Overall, results indicate that no catastrophic behaviour is observed and that such components are capable of fulfilling their steady-state design requirements for plasma loading.

\section{Acknowledgements}

The actively-cooled monoblock chain was supplied by the ITER Organization and F4E as part of a EUROfusion-funded experiment to investigate the effect of ITER-relevant fluences on the properties of tungsten. This work has been carried out within the framework of the EUROfusion Consortium and has received funding from the Euratom research and training programme 2014-2018 and 2019-2020 under grant agreement No 633053. Work partly performed under EUROfusion WP PFC. The views and opinions expressed herein do not necessarily reflect those of the European Commission or of the ITER Organization.

\section{References}

[1] Pitts R A, Carpentier S, Escourbiac F, Hirai T, Komarov V, Lisgo S, Kukushkin A S, Loarte A, Merola M, Sashala Naik A, Mitteau R, Sugihara M, Bazylev B and Stangeby P C 2013 J. Nucl. Mater. 438 S48-56

[2] Hirai T, Escourbiac F, Carpentier-Chouchana S, Fedosov A, Ferrand L, Jokinen T, Komarov V, Kukushkin A, Merola M, Mitteau R, Pitts R A, Shu W, Sugihara M, Riccardi B, Suzuki S and Villari R 2013 Fusion Eng. Des. 88 1798-801

[3] Pitts R A, Carpentier S, Escourbiac F, Hirai T, Komarov V, Kukushkin A S, Lisgo S, Loarte A, Merola M, Mitteau R, Raffray A R, Shimada M and Stangeby P C 2011 J. Nucl. Mater. 415 S957-64

[4] Merola M, Escourbiac F, Raffray R, Chappuis P, Hirai T and Martin A 2014 Fusion Eng. Des. 89 890-5

[5] Condon J B and Schober T 1993 J. Nucl. Mater. 207 $1-24$

[6] Skinner C H, Haasz A A, Almov V K H, Bekris N, Causey R A, Clark R E H, Coad J P, Davis J W, Doerner R P, Mayer M, Pisarev A, Roth J and Tanabe T 2008 Fusion Sci. Technol. 54 891-945

[7] Shu W M 2008 Appl. Phys. Lett. 92 1-4

[8] Alimov V K, Tyburska-Püschel B, Lindig S, Hatano Y, Balden M, Roth J, Isobe K, Matsuyama M and Yamanishi T 2012 J. Nucl. Mater. 420 519-24

[9] Jia Y Z, Liu W, Xu B, Qu S L, Shi L . and Morgan T W 2017 Nucl. Fusion 57034003

[10] Balden M, Manhard A and Elgeti S 2014 J. Nucl. Mater. 452 248-56

[11] Behrisch R 1981 Sputtering by Particle 
Bombardment I Physical Sputtering of SingleElement Solids (Berin Heidelberg New York: Springer)

[12] Sigmund P 1987 Nucl. Inst. Methods Phys. Res. B 27 1-20

[13] Behrisch R and Eckstein W 2007 Sputtering by particle bombardment vol 110 (Berlin: Springer)

[14] Takamura S, Ohno N, Nishijima D and Kajita S 2006 Plasma Fusion Res. 1 051-051

[15] Baldwin M J and Doerner R P 2008 Nucl. Fusion 48 035001

[16] Kajita S, Sakaguchi W, Ohno N, Yoshida N and Saeki T 2009 Nucl. Fusion 49095005

[17] Baldwin M J, Doerner R P, Nishijima D, Tokunaga K and Ueda Y 2009 J. Nucl. Mater. 390-391 886-90

[18] Ueda Y, Coenen J W, De Temmerman G, Doerner R P, Linke J, Philipps V and Tsitrone E 2014 Fusion Eng. Des. 89 901-6

[19] Petty T J, Baldwin M J, Hasan M I, Doerner R P and Bradley J W 2015 Nucl. Fusion 55093033

[20] Meyer F W 2019 J. Phys. B At. Mol. Opt. Phys. 52 12001

[21] De Temmerman G, Hirai T and Pitts R A 2018

Plasma Phys. Control. Fusion 60044018

[22] van de Pol M J J, Alonso van der Westen S, Aussems D U B, van den Berg M A, Brons S, van Eck H J N, van Eden G G, Genuit H J W, van der Meiden H J, Morgan T W, Scholten J, Vernimmen J W M, Vos E G P G P and de Baar M R R 2018 Fusion Eng. Des. 136 597-601

[23] van Eck H J N, Akkermans G R A, Alonso van der Westen S, Aussems D U B, van Berkel M, Brons S, Classen I G J, van der Meiden H J, Morgan T W, van der Pol M J, Scholten J, Vernimmen J W M, Vos E G P and de Baar M R 2019 Fusion Eng. Des. 142 26-32

[24] ITER Organization 2018 ITER Research Plan within the Staged Approach (ITR-18-003)

[25] De Temmerman G, Van Den Berg M A, Scholten J, Lof A, Van Der Meiden H J, Van Eck H J N, Morgan T W, de Kruijf T M, Zeijlmans Van Emmichoven P A and Zielinski J J 2013 Fusion Eng. Des. 88 483-7

[26] Pacher H D, Kukushkin A S, Pacher G W, Kotov V, Pitts R A and Reiter D 2015 J. Nucl. Mater. 463 591-5

[27] Loewenhoff T, Bardin S, Greuner H, Linke J, Maier H, Morgan T W, Pintsuk G, Pitts R A, Riccardi B and De Temmerman G 2015 Nucl. Fusion 55123004

[28] Van Eck H J N, Koppers W R, Van Rooij G J, Goedheer W J, Engeln R, Schram D C, Cardozo N J L and Kleyn A W 2009 J. Appl. Phys. 105063307

[29] Balden M, Elgeti S, Morgan T W, Brezinsek S and De Temmerman G 2019 Phys. Scr. (current)

[30] Loewenhoff T, Antusch S, Pintsuk G, Rieth M and Wirtz M 2019 Nucl. Mater. Energy 20100680

[31] ITER Organization 2013 ITER material properties handbook (ITER document G 74 MA 8 01-05-28 W
0.2)

[32] Lipschultz B, Roth J, Davis J W, Doerner R P, Haasz A A, Kallenbach A, Kirschner A, Kolasinski R D, Loarte A, Philipps V, Schmid K, Wampler W R, Wright G M and Whyte1 D G 2010 An Assessment of the Current Data Affecting Tritium Retention and its Use to Project Towards T Retention in ITER (MIT Rep. PSFC/RR-10-4)

[33] Buzi L, De Temmerman G, Unterberg B, Reinhart M, Dittmar T, Matveev D, Linsmeier C, Breuer U, Kreter A and Van Oost G 2015 J. Nucl. Mater. 463 320-4

[34] Lee H T, Haasz A A, Davis J W, MacaulayNewcombe R G, Whyte D G and Wright G M 2007 J. Nucl. Mater. 363-365 898-903

[35] Alimov V K, Shu W M, Roth J, Sugiyama K, Lindig S, Balden M, Isobe K and Yamanishi T 2009 Phys. Scr. T138 014048

[36] Ueda Y, Fukumoto M, Yoshida J, Ohtsuka Y, Akiyoshi R, Iwakiri H and Yoshida N 2009 J. Nucl. Mater. 386-388 725-8

[37] Baldwin M J, Doerner R P, Wampler W R, Nishijima D, Lynch T and Miyamoto M 2011 Nucl. Fusion 51103021

[38] Markelj S, Schwarz-Selinger T and Založnik A 2017 Nucl. Fusion 57064002

[39] Stangeby P C 2000 The Plasma Boundary of Magnetic Fusion Devices (Bristol, UK: IOP Publishing)

[40] Thompson M, Deslandes A, Morgan T W, Elliman R G, De Temmerman G, Kluth P, Riley D and Corr C S 2016 Nucl. Fusion $\mathbf{5 6}$

[41] Costin C, Anita V, Ghiorghiu F, Popa G, De Temmerman G, van den Berg $\mathrm{M}$ a, Scholten $\mathrm{J}$ and Brons S 2015 Plasma Sources Sci. Technol. 24 015014

[42] Costin C, Anita V, Popa G, Scholten J and De Temmerman G 2016 Plasma Sources Sci. Technol. 25025023

[43] Kajita S, Yoshida N, Yoshihara R, Ohno N, Yokochi T, Tokitani M and Takamura S $2012 \mathrm{~J}$. Nucl. Mater. 421 22-7

[44] Kajita S, Yoshida N, Yoshihara R, Ohno N and Yamagiwa M 2011 J. Nucl. Mater. 418 152-8

[45] Krasheninnikov S I 2011 Phys. Scr. T145 014040

[46] De Temmerman G, Doerner R P and Pitts R A 2019 Nucl. Mater. Energy 19 255-61

[47] Kajita S, Kawaguchi S, Ohno N and Yoshida N 2018 Sci. Rep. 8 1-9

[48] Doerner R P, Nishijima D, Krasheninnikov S I, Schwarz-Selinger T and Zach M 2018 Nucl. Fusion 58

[49] Takamura S 2014 Plasma Fusion Res. 9 1-4

[50] De Temmerman G, Bystrov K, Zielinski J J, Balden M, Matern G, Arnas C and Marot L 2012 J. Vac. Sci. Technol. A Vacuum, Surfaces, Film. 30041306

[51] Woller K B, Whyte D G and Wright G M 2017 Nucl. Fusion 57066005 
[52] Hwangbo D, Ohno N, Tanaka H, Kajita S, McCarthy P and Bradley J W 2018 Nucl. Fusion 58 096022

[53] Ohno N, Hirahata Y, Yamagiwa M, Kajita S, Takagi M, Yoshida N, Yoshihara R, Tokunaga T and Tokitani M 2013 J. Nucl. Mater. 438 S879-82

[54] Baldwin M J and Doerner R P 2010 J. Nucl. Mater. 404 165-73

[55] Takamura S and Miyamoto T 2011 Plasma Fusion Res. Rapid Commun. 61202005

[56] Summers H P 2004 The ADAS User Manual, version 2.6 http://adas.ac.uk. (accessed 16-06-2017)

[57] Alfonso A, Juul Jensen D, Luo G N and Pantleon W 2014 J. Nucl. Mater. 455 591-4

[58] Alfonso A, Juul Jensen D, Luo G N and Pantleon W 2015 Fusion Eng. Des. 98-99 1924-8

[59] Pintsuk G, Antusch S, Weingaertner T and Wirtz M 2018 Int. J. Refract. Met. Hard Mater. 72 97-103

[60] Panayotis S, Hirai T, Barabash V, Durocher A, Escourbiac F, Linke J, Loewenhoff T, Merola M, Pintsuk G, Uytdenhoven I and Wirtz M 2017 Nucl. Mater. Energy 12 200-4

[61] Guo W, Cheng L, De Temmerman G, Yuan Y and Lu G H 2018 Nucl. Fusion 58106011

[62] Goltsov V A, Glyakov D A and Zhirov G I 2006 Int. J. Hydrogen Energy 31 211-6

[63] Wen J 2017 Effect of Hydrogen on the Microstructure and Cold Rolling Behavior of Commercially Pure Titanium and $\beta$-metastable Titanium Alloy (Universite de Lorraine)

[64] Hirooka Y and Zhou H 2014 Fusion Sci. Technol. 66 63-9

[65] Zhou H S, Liu H D, An Z Q, Li B, Xu Y P, Liu F, Zhao M Z, Xu Q, Ding F and Luo G N 2017 J. Nucl. Mater. 493 398-403

[66] Panayotis S, Hirai T, Barabash V, Amzallag C, Escourbiac F, Durocher A, Komarov V, Martinez J M and Merola M 2017 Fusion Eng. Des. 125 256-62 